\title{
Articles
}

\section{Birthweight of offspring and paternal insulin resistance and paternal diabetes in late adulthood: cross sectional survey}

\author{
S. G. Wannamethee ${ }^{1}$, D. A. Lawlor ${ }^{1,2}$, P. H. Whincup ${ }^{1,3}$, M. Walker ${ }^{1}$, S. Ebrahim ${ }^{1,2}$, G. Davey-Smith ${ }^{1,2}$ \\ ${ }^{1}$ Department of Primary Care and Population Science, Royal Free and University College Medical School, London, UK \\ ${ }^{2}$ Department of Social Medicine, University of Bristol, Bristol, UK \\ ${ }^{3}$ Department of Public Health Sciences, St George's Medical School Hospital, London, UK
}

\section{Abstract}

Aims/hypothesis. It has been proposed that genetic factors involved in insulin action could explain part of the link between low birthweight and risk of cardiovascular disease and diabetes in adulthood. To confirm this we examined the association between offspring birthweight and paternal insulin resistance and diabetes in late adulthood.

Methods. We did a cross-sectional survey of 4252 men who were 60 to 79 years of age and from 24 British towns. Of these, 2788 men provided details of their offsprings' birthweight and sex.

Results. Offspring birthweight was inversely associated with paternal insulin resistance defined by the homeostasis model assessment (HOMA) score and with Type 2 diabetes in late adulthood. Fathers of offspring in the highest quartile of sex-standardised birthweight SD scores had a $34 \%$ reduction in odds of having a high HOMA insulin resistance score $(\mathrm{OR}=0.66,95 \%$
CI: 0.47 to 0.92 ) compared with fathers of offspring in the lowest quartile after adjustment for potential confounders. A stronger inverse association was seen between offspring birthweight and risk of paternal diabetes (adjusted OR $=0.59,95 \% \mathrm{CI}: 0.39$ to 0.88 top quartile vs lowest quartile). For each increase of offspringbirthweight SD score the odds of high HOMA scores decreased by $13 \%$ (OR=0.87, 95\% CI: 0.78 to 0.98 ) and the odds for diabetes by $17 \%(\mathrm{OR}=0.83,95 \% \mathrm{CI}$ : 0.72 to 0.95 ), after full adjustment.

Conclusions/interpretation. Offspring birthweight is inversely associated with paternal insulin resistance and diabetes in late adulthood, supporting the hypothesis that genetic factors related to insulin action contribute to the association between birthweight and adult cardiovascular disease and diabetes risk. [Diabetologia (2004) 47:12-18]

Keywords Offspring birthweight - paternal insulin resistance - Type 2 diabetes
Low birthweight is associated with increased risks of adult cardiovascular disease and diabetes in adulthood, but the extent to which this relationship reflects intrauterine programming of disease risk [1] and/or

Received: 16 June 2003 / Revised: 8 September 2003

Published online: 26 November 2003

C) Springer-Verlag 2003

Dr. S. G. Wannamethee ( $)$, Department of Primary Care and Population Science, Royal Free and University College Medical School, Rowland Hill St, London, NW3 2PF, UK

E-mail: goya@pcps.ucl.ac.uk

Abbreviations: HOMA, homeostasis model assessment; OR, odds ratio; Q, questionnaire. common genetic factors is not known [2]. Several studies have shown that low offspring birthweight is also associated with parental cardiovascular disease and diabetes $[3,4,5,6,7,8,9]$. These associations between low offspring birthweight and parental risk cannot be explained by programming, as an infant's low birthweight cannot possibly programme its own parents' risk of cardiovascular disease. They could, however, be explained either by adverse environmental influences operating across the parental life course and affecting both adult and offspring health outcomes, or by the presence of genetic polymorphisms influencing adult cardiovascular risk and fetal growth.

A potential example of the latter is the fetal insulin hypothesis (in which polymorphisms produce parental 
insulin resistance and impaired insulin-mediated fetal growth) [2]. Though a relation between maternal diabetes and insulin resistance on the one hand, and low offspring birthweight on the other has been observed [7], information on fathers is limited [8, 9]. Studies of men have been limited by low statistical power, selfreported diagnoses of diabetes, or because they were done in atypical populations with a high risk of Type 2 diabetes. It is of particular interest to compare the strengths of these associations in men and women within similar populations because a relationship in women could be explained by direct intrauterine influences on birthweight, which cannot be the case for men. Our investigation of the relationships between paternal insulin resistance, paternal diabetes and offspring birthweight among older men was done in a cohort parallel to one in which women were studied and from which data on these relations have been reported [7].

\section{Subjects and methods}

Study cohort. The British Regional Heart Study is a prospective study of cardiovascular disease involving 7735 men of 40 to 59 years of age and selected from the age and sex registers of one general practice in each of 24 British towns. These men were screened between 1978 and 1980 [10]. Ethics approval was provided by all relevant local research ethics committees. All men provided informed written consent to the investigation, which was carried out in accordance with the Declaration of Helsinki. Research nurses collected information by means of a standard questionnaire including questions on physical activity, smoking and medical history. All men have been followed up for all-cause mortality, cardiovascular morbidity and development of Type 2 diabetes since the initial screening [11]. During follow-up, similar questionnaires were mailed to the men between 1983 and 1985 (Q5), in 1992 (Q92), and again in 1996 (Q96). Between 1998 and 2000 all surviving men, now 60 to 79 years of age, were invited for a 20th year follow-up examination, carried out in a local health centre. All men attending the 20th year follow-up completed a mailed questionnaire $(\mathrm{Q} 20)$ providing information on their medical history, smoking and drinking habits, physical activity and occupation. They also had a physical examination and provided a fasting blood sample. These men were asked to fast for a minimum of $6 \mathrm{~h}$, drinking only water, and to attend for measurement at a pre-specified time between 08.00 and 20.00 hours. Blood samples were collected using the Sarstedt Monovette system. Of the 5565 surviving subjects, 4252 (77\%) attended for examination. In this recent re-examination men were asked for the first time about details of their offsprings' birthweight and sex. Our analysis uses cross-sectional data from the 1998 to 2000 re-examination of cohort survivors.

Cardiovascular risk factors. Details of classification methods for smoking status, alcohol consumption, physical activity, BMI and adult and father's social class have been described previously $[10,12,13]$.

Two seated blood pressure measurements were made with a one-minute interval using the Dinamap 1846 (Critikon, Critikon Services, Berkshire, UK) and using a cuff size consistent with American Heart Association guidelines [14]. Blood pressure was adjusted for observer variation. Plasma (fluorideoxalate) was collected to measure glucose. Serum was collected to measure lipids and insulin. Total cholesterol, HDL cholesterol and triglycerides were measured using a Hitachi 747 automated analyser (Hitachi, Tokyo, Japan) and reagents supplied by Roche Diagnostics (Basel, Switzerland). Total Cholesterol and HDL cholesterol were measured using established methods $[15,16]$. LDL cholesterol values were calculated using the Fredrickson-Friedewald equation [17]. Plasma glucose was measured by the glucose oxidase Trinder method [18] using a Falcor 600 automated analyzer (A. Menarini Diagnostics, Wokingham, UK). Serum insulin was measured using an ELISA assay which does not cross-react with proinsulin [19]. LDL cholesterol, triglycerides, insulin and glucose values were adjusted for the effects of fasting duration and time of day [20].

Offspring birthweight. At the re-examination between 1998 and 2000 the men were asked to provide details of the birthweights and sex of their children. To be consistent with other research in this area [7], and because of systematic increases in birthweight with increasing parity, we used details of the firstborn offspring for the main analysis. Of the 4252 men who participated, 444 indicated that the question was not applicable (presumed childless). Of the remaining 3808 men 3015 (79\%) provided details of their firstborn's birthweight. In nine subjects the offspring's birthweight was less than $1500 \mathrm{~g}$, and these subjects were removed from the analysis. A total of 218 men failed to provide details on the sex of the child and were also excluded, leaving 2788 men for analyses. The sex of the offspring included was as follows: $1474(52.9 \%)$ were male with a mean birthweight of $3.36 \mathrm{~kg}$ (SD 0.52); 1314 were female with a mean birthweight of $3.25 \mathrm{~kg}$ (SD 0.50).

Outcome. Information on prevalent diabetes was based on review of general practice medical records between initial screening in 1978 to 1980 and the return of Q20, and also on recall by the subject of physician-diagnosed diabetes (obtained by completion of Q20). Insulin resistance was estimated according to the homeostasis model assessment (HOMA) as the product of fasting glucose $(\mathrm{mmol} / \mathrm{l})$ and insulin $(\mu \mathrm{U} / \mathrm{ml})$ divided by the constant 22.5 [21]. HOMA scores were not calculated for diabetic men and men with fasting glucose above $7 \mathrm{mmol} / \mathrm{l}$, because in a study of older men (mean age 61 years) HOMA scores in men with glucose intolerance or diabetes were only weakly correlated with euglycaemic clamp assessment $\left(r_{s}=0.13\right)$ [21]. Men with a doctor's diagnosis of diabetes (GP reporting at any of the biennial record reviews or recall at any of the questionnaire surveys) and men with a fasting glucose above $7 \mathrm{mmol} / \mathrm{l}$ were all considered to have prevalent diabetes in this study [22].

Statistical analysis. Since birthweight is higher on average in male neonates we standardised birthweight for sex by expressing offspring birthweight as an SD score or $z$ score. Sex-specific SD scores ( $z$ scores) were derived for each offspring's birthweight. The SD score was calculated as individual's offspring birthweight minus sex-specific mean offspring birthweight for the cohort divided by the sex-specific standard deviation of offspring birthweight for the cohort. A unit increase in birthweight SD score is an increase of 1 SD of birthweight standardised for sex. HOMA scores and triglyceride concentrations were log normal: geometric means are presented and the natural $\log$ of the concentrations were used in the regression models. Subjects were defined as having high insulin resistance if they were in the top quartile of HOMA scores. Age-adjusted means of insulin resistance (HOMA score) and means and 
prevalence of other cardiovascular disease risk factors are presented across quartiles of offspring birthweight SD score.

Age-adjusted trends across quartiles of birthweight SD score were examined using multiple linear regression for continuous variables and multiple logistic regression for categorical variables. Multiple logistic regression was used to estimate the relative odds of high insulin resistance and diabetes for the quartiles and the relative odds per 1 unit increase in offspring birthweight SD score, with adjustment for potential confounding factors. In these models age, BMI, waist-to-hip ratio, systolic and diastolic blood pressure, HDL cholesterol, LDL cholesterol and triglycerides (logged) were entered as continuous variables. The following were entered as categorical variables: adult (based on longest held occupation) and childhood (based on father's longest held occupation) social class (I, II, III nonmanual vs III manual, IV, V and armed forces), physical activity (five levels: none, occasional, light, moderate, moderately vigorous to vigorous), alcohol intake (five levels: 0 drinks per day, less than 1 drink per day, 1 to 2 drinks per day, 3 to 4 drinks per day, 5 or more drinks per day; 1 drink $=$ half a pint of beer or 1 glass of wine or 1 measure of spirits) and current smoking (yes/no). "Active" was defined as those reporting at least moderate levels of activity. All analyses were carried out using the SAS software version 8.2 (SAS Institute, Carey, N.C., USA).

\section{Results}

Paternal characteristics. Men who provided details of offspring birthweight were younger than men who did not (68.4 vs 69.4 years), but there was little difference in age-adjusted mean HOMA score or prevalence of diabetes between the two groups. There were 305 prevalent cases of diabetes (197 doctor diagnosis, 108 by blood glucose above $7 \mathrm{mmol} / \mathrm{l}$ ) among the 2788 men providing details of offspring birthweight. The offspring of fathers who developed diabetes in later adult life were on average lighter than the offspring of non-diabetic fathers (age-adjusted mean SD score -0.128 vs $0.01 ; p=0.02)$.

Association between offspring birthweight and paternal insulin resistance and paternal diabetes. Table 1 shows the relationship between offspring birthweight $z$ score divided into quartiles and age-adjusted HOMA scores, prevalence of diabetes and other cardiovascular disease risk factors. Fathers with heavier babies tended to be less insulin resistant. Although the differences in absolute mean HOMA between the birthweight quartiles were small, the difference in percentage of men with high levels (defined as the top quartile of the distribution) was more marked. Fathers with heavier babies were less likely to have a high HOMA score (marginal significance) and less likely to be diabetic than fathers of lighter babies ( $p=0.02)$. They were taller, had higher waist-to-hip ratios than fathers of lighter babies and were more likely to be active, have higher BMI and belong to non-manual social classes in childhood and adulthood, although these latter trends were not statistically significant at the conventional 5\% level.

Table 1. Age-standardised mean or prevalence of paternal insulin resistance, diabetes and other paternal characteristics by quartiles of offspring birthweight standard deviation score

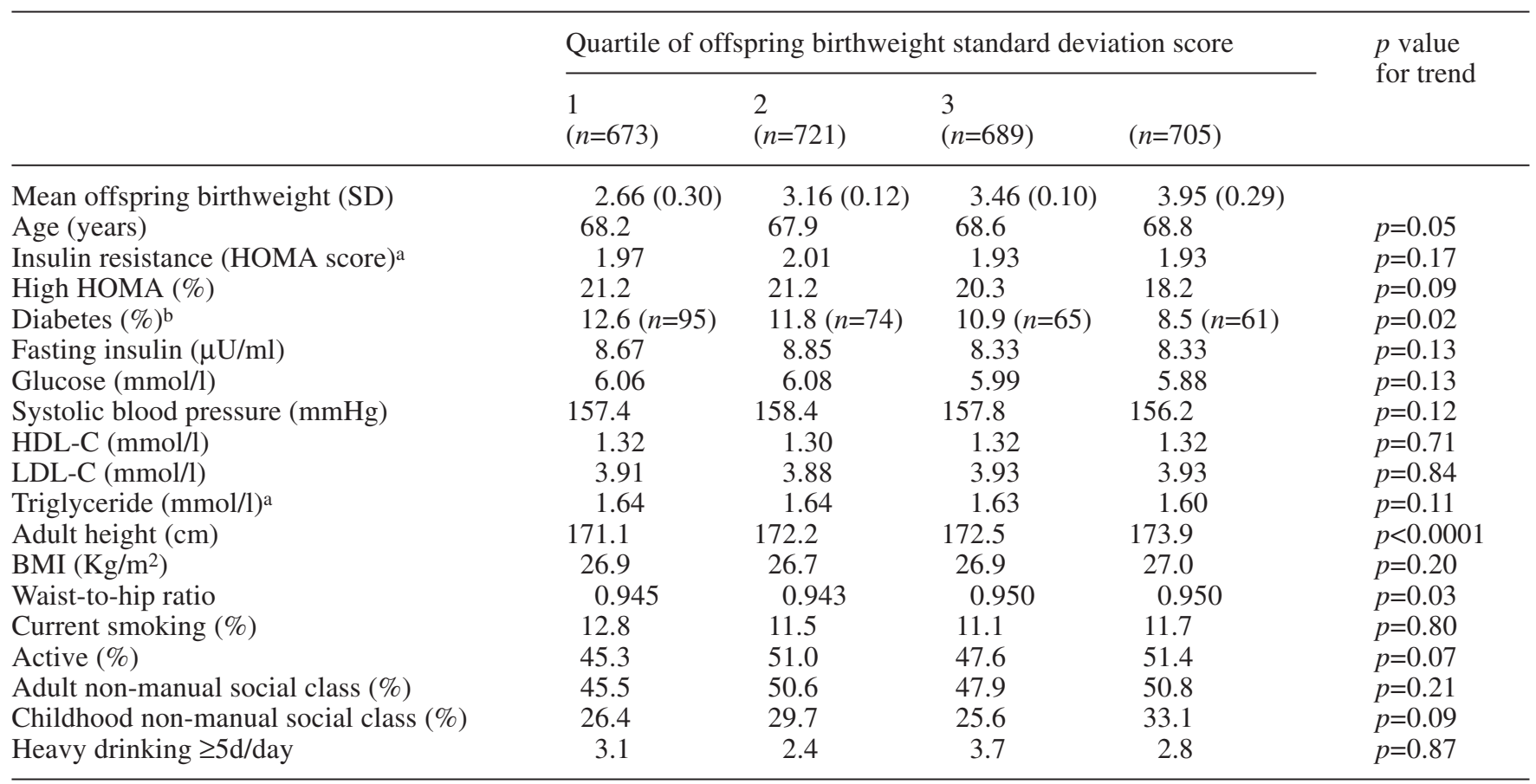

a Geometric mean; b doctor diagnosis of diabetes or fasting glucose $>7 \mathrm{mmol} / \mathrm{l}$. HOMA, homeostasis model assessment; LDL-C, low density lipoprotein cholesterol; HDL-C, high den- sity lipoprotein cholesterol; d/day, drink per day (1 drink=half a pint of beer, 1 glass of wine or 1 measure of spirits) 
Table 2. Adjusted mean HOMA by quartiles of offspring birthweight SD score

\begin{tabular}{|c|c|c|c|c|c|c|}
\hline & \multicolumn{4}{|c|}{$\begin{array}{l}\text { Offspring birthweight standard deviation score (quartiles), } \\
\text { mean HOMA score (geometric mean) }\end{array}$} & \multirow{2}{*}{$\begin{array}{l}\text { Difference per } \\
1 \text { unit increase } \\
\text { in offspring } \\
\text { birthweight SD } \\
\text { score }\end{array}$} & \multirow[t]{2}{*}{ Linear trend } \\
\hline & $\begin{array}{l}1 \\
(n=673)\end{array}$ & $\begin{array}{l}2 \\
(n=721)\end{array}$ & $\begin{array}{l}3 \\
(n=689)\end{array}$ & $\begin{array}{l}4 \\
(n=705)\end{array}$ & & \\
\hline Age-adjusted & 1.97 & 2.01 & 1.93 & 1.93 & $-0.017(0.012)$ & $p=0.17$ \\
\hline Age+BMI+waist-to-hip ratio & 1.97 & 2.05 & 1.92 & 1.91 & $-0.018(0.018)$ & $p=0.04$ \\
\hline
\end{tabular}

(+) adjusted for age, BMI, waist-to-hip ratio, adult height, adult social class, father's social class, cigarette smoking, physical activity, alcohol intake, systolic blood pressure, triglyceride, HDL cholesterol and LDL cholesterol.
SD for male offspring: 0.52 ; SD for female offspring: 0.50 ; HOMA, homeostasis model assessment

Table 3. Adjusted relative odds of being in the top quartile of the distribution of the HOMA score and adjusted relative odds of prevalent diabetes by quartiles of offspring birthweight SD score

\begin{tabular}{|c|c|c|c|c|c|c|}
\hline & \multicolumn{4}{|c|}{$\begin{array}{l}\text { Offspring birthweight standard deviation score (quartiles), } \\
\text { adjusted relative odds ( } 95 \% \mathrm{CI})\end{array}$} & \multirow{2}{*}{$\begin{array}{l}\text { Odds ratio per } \\
1 \text { unit increase } \\
\text { in offspring } \\
\text { birthweight SD } \\
\text { score }\end{array}$} & \multirow[t]{2}{*}{$\begin{array}{l}\text { Linear } \\
\text { trend }\end{array}$} \\
\hline & $\begin{array}{l}1 \\
(n=673)\end{array}$ & $\begin{array}{l}2 \\
(n=721)\end{array}$ & $\begin{array}{l}3 \\
(n=689)\end{array}$ & $\begin{array}{l}4 \\
(n=705)\end{array}$ & & \\
\hline \multicolumn{7}{|l|}{ High HOMA } \\
\hline Age+BMI+waist-to-hip ratio & 1.00 & $\begin{array}{l}1.05 \\
(0.79 \text { to } 1.40)\end{array}$ & $\begin{array}{l}0.91 \\
(0.68 \text { to } 1.22)\end{array}$ & $\begin{array}{l}0.75 \\
(0.56 \text { to } 1.00)\end{array}$ & $\begin{array}{l}0.89 \\
(0.81 \text { to } 0.99)\end{array}$ & $p=0.03$ \\
\hline Adjusted (+) & 1.00 & $\begin{array}{l}1.03 \\
(0.76 \text { to } 1.41)\end{array}$ & $\begin{array}{l}0.89 \\
(0.65 \text { to } 1.23)\end{array}$ & $\begin{array}{l}0.66 \\
(0.47 \text { to } 0.92)\end{array}$ & $\begin{array}{l}0.87 \\
(0.78 \text { to } 0.98)\end{array}$ & $p=0.02$ \\
\hline \multicolumn{7}{|l|}{ Diabetes } \\
\hline Adjusted (+) & 1.00 & $\begin{array}{l}0.96 \\
(0.67 \text { to } 1.37)\end{array}$ & $\begin{array}{l}0.72 \\
(0.49 \text { to } 1.06)\end{array}$ & $\begin{array}{l}0.59 \\
(0.39 \text { to } 0.88)\end{array}$ & $\begin{array}{l}0.83 \\
(0.72 \text { to } 0.95)\end{array}$ & $p=0.008$ \\
\hline
\end{tabular}

(+) adjusted for age, BMI, waist-to-hip ratio, adult height, adult social class, father's social class, cigarette smoking, physical activity, alcohol intake, systolic blood pressure, trigly-

An inverse association was seen with fasting insulin and blood glucose although the trend was not statistically significant. No association was seen between offspring birthweight and blood lipids and blood pressure, although fathers with the heaviest babies had the lowest mean blood pressure. Because BMI and waistto-hip ratio are strongly and positively associated with hyperinsulinaemia and diabetes, the inverse association between the HOMA score and diabetes prevalence and offspring birthweight was strengthened by adjustment for waist-to-hip ratio and current BMI (Table 2). Adjustment further strengthened the inverse relationship seen with fasting insulin ( $p=0.02$ for trend) and blood glucose ( $p=0.08$ for trend), which is consistent with the inverse relationship seen with HOMA. ceride, HDL cholesterol and LDL cholesterol. SD for male offspring: 0.52; SD for female offspring: 0.50; HOMA, homeostasis model assessment

The age-adjusted odds of developing insulin resistance (top quartile of HOMA) for fathers with offspring birthweight in the top quartile compared with the bottom quartile was 0.80 and this strengthened to 0.75 after adjustment for BMI and waist-to-hip ratio (Table 3). This relationship persisted even after full adjustment for other potential confounding factors (systolic blood pressure, diastolic blood pressure, HDL cholesterol, LDL cholesterol, triglycerides, smoking, adult height, adult social class, childhood social class, physical activity and heavy drinking) [adjusted odds ratio $(\mathrm{OR})=0.66,95 \% \mathrm{CI}: 0.47$ to 0.92 ]. A stronger and more progressive inverse relationship was seen with diabetes (adjusted $\mathrm{OR}=0.59,95 \% \mathrm{CI}$ : 0.39 to 0.88 top quartile vs bottom quartile). For each unit increase in 
birthweight SD score, i.e. increase in $1 \mathrm{SD}$ of birthweight for sex, the odds of high HOMA decreased by $13 \%$ (OR=0.87, 95\% CI: 0.78 to 0.98$)$ and the odds for diabetes decreased by $17 \%(\mathrm{OR}=0.83,95 \% \mathrm{CI}$ : 0.72 to 0.95), after full adjustment.

We repeated the analyses for the second-born child ( $n=2,388 \mathrm{men})$ and third-born child ( $n=998 \mathrm{men})$. The inverse relationship between offspring birthweight and diabetes and insulin resistance (HOMA) was similar for the second- and third-born offspring birthweight. The fully adjusted mean differences in offspring birthweight SD score between diabetic and non-diabetic subjects were: $-0.17(0.07)(p=0.01),-0.14(0.08)$ $(p=0.06)$ and $-0.14(0.07)(p=0.06)$ for the first, second and third-born offspring respectively.

\section{Discussion}

Our finding that offspring birthweight is inversely associated with paternal insulin resistance and diabetes in later life is consistent with the fetal insulin hypothesis, namely that genetic factors related to both insulin resistance and birthweight explain at least part of the association between birthweight and adult cardiovascular disease and diabetes risk [2].

In a recent cohort of women of the same age and from similar British towns to the men in this study, offspring birthweight was inversely associated with maternal insulin resistance but a U-shaped relationship was seen with maternal diabetes[7], possibly reflecting the known association between impaired glucose tolerance in mothers and greater offspring birthweight $[23,24]$. We also observed an inverse relationship between offspring birthweight and (paternal) insulin resistance, but in contrast to the other study an even stronger inverse association was seen between offspring birthweight and (paternal) diabetes. Studies carried out in the mid-twentieth century [25, 26] found that the offspring of diabetic men had higher birthweights than the offspring of control subjects, but a high proportion of men in this age group would have Type 1 diabetes [27]. For individuals higher birthweight is associated with the risk of developing Type 1 diabetes [28], and if common genetic factors are involved, it is factors related to increased birthweight and increased risk of Type 1 diabetes. Type 2 diabetes, on the other hand, is associated with lower individual birthweight [1] and with greater risk of Type 2 diabetes among fathers $[8,9]$. As in the intergenerational cohort study [9], a child's birth order made little difference to the effect of its father's diabetes on the birthweight of his offspring.

The association between paternal risk of Type 2 diabetes and offspring birthweight could reflect a common environmental influence on diabetes risk and offspring birthweight. However, our study found only weak associations between adult social class and childhood social class on the one hand, and offspring birthweight on the other. Moreover, neither adult social class nor childhood social class showed any association with prevalence of diabetes in this present cohort. In an earlier prospective report from this cohort of men at age 40 to 59 years no association was seen between adult social class and 12-year incidence of diabetes [29]. Thus the most plausible explanation for an association between offspring birthweight and a father's diabetes risk and increased risk of insulin resistance is common genetic factors which affect insulin action and also lead to impaired insulin-mediated fetal growth [2]. The relationship cannot be explained, as in women, by a direct link between maternal metabolic status and intrauterine control of fetal size.

A potential study limitation is the fact that we used cross-sectional data collected from survivors of a 20year-old cohort. Our results could therefore be affected by survivor bias. If, for example, offspring birthweight were associated with survival, as well as with occurrence of diabetes and increased insulin resistance, it is possible that our results underestimate the true associations. Another possible limitation is our reliance upon paternal recall of offspring birthweight, which could be inaccurate, particularly if a father relied on his own recall only (without asking the child's mother) [30]. The mean age of the men in our study is 69 years; many of these men will have had their firstborn offspring in the 1950's. Mean birthweight for boys and girls included in the 1958 British birth cohort are similar to those reported for offspring in our study: $3.40 \mathrm{~kg}$ (SD $0.45 \mathrm{~kg}$ ) for boys in the 58 cohort compared to $3.36 \mathrm{~kg}$ ( $\mathrm{SD} 0.52 \mathrm{~kg}$ ) in our study, and $3.26 \mathrm{~kg}$ (SD $0.43 \mathrm{~kg}$ ) compared to $3.25 \mathrm{~kg}$ (SD $0.50 \mathrm{~kg}$ ) for girls) [31]. This similarity suggests that paternal recall of offspring birthweight is unlikely to have biased our results. Any misclassification of offspring birthweight is not likely to be related to paternal diabetes or insulin resistance status and would therefore be non-differential and tend to dilute the true association.

In addition, we do not have data on gestational age of the offspring of the men in this study. However, birthweight adjusted for gestational age in other cohorts has tended to be more strongly inversely associated with CHD than birthweight alone [32, 33]. If the association between offspring birthweight and insulin resistance operates through similar mechanisms to that between own birthweight and coronary heart disease, our results could again underestimate the true association.

Although we cannot separate Type 1 and Type 2 diabetes with certainty, the overwhelming majority of our cases were Type 2 diabetes. Exclusion of men who developed diabetes before age 40 and of men on insulin ( $n=28$ cases) should effectively exclude most subjects with Type 1 diabetes. Doing this further strengthened the association between offspring birth- 
weight and diabetes $(\mathrm{OR}=0.55,95 \% \mathrm{CI}: 0.36$ to 0.85 (top quartile vs bottom quartile).

Definitive proof of the fetal insulin hypothesis requires the identification of candidate genes associated with birthweight and insulin resistance. A mutation in the glucokinase gene which results in increased risk of Type 2 diabetes has been shown to be associated with low birthweight [34]. Although this supports the argument, this mutation is rare and cannot explain the association between low birthweight, insulin resistance and cardiovascular disease risk in the general population. The association of a number of candidate genes involved in insulin metabolism with birth size has been examined, but with inconsistent results [35, 36, $37,38]$. To date genetic factors that could explain this association in the general population have not been established.

In conclusion, our study provides important epidemiological evidence consistent with the fetal insulin hypothesis. Our findings indicate that at least some of the associations between the birthweight of individuals and their later risk of diabetes and cardiovascular disease seen in other studies could be genetic and therefore not modifiable by interventions targeting maternal health or intrauterine development. Our findings should also encourage the search for specific polymorphisms associated with birthweight, insulin resistance and cardiovascular disease.

Acknowledgements. The British Regional Heart Study is a Research Group funded by the British Heart Foundation and receives support from the Department of Health, England. D. A. Lawlor is funded by a Medical Research Council and Department of Health training fellowship. The views expressed in this study are those of the authors and not necessarily those of the Department of Health or Medical Research Council.

Contributors: S.G. Wannamethee did the statistical analyses and wrote the initial draft with D.A. Lawlor. D.A. Lawlor, S. Ebrahim and G. Davey-Smith developed the initial idea for the paper and contributed to the writing of it. P.H. Whincup designed the study and contributed to its writing. M. Walker was study coordinator and responsible for the follow-up questionnaire data collection.

\section{References}

1. Barker DJP (1998) Mothers, babies and health in later life, 2nd edn. Churchill Livingstone, Edinburgh

2. Hattersley AT, Tooke JE (1999) The fetal insulin hypothesis: an alternative explanation of the association of low birthweight with diabetes and vascular disease. Lancet 353: 1789-1792

3. Davey Smith G, Hart C, Ferrell C et al. (1997) Birth weight of offspring and mortality in the Renfrew and Paisley study: prospective observational study. BMJ 315:1189-1193

4. Smith GD, Harding S, Rosato M (2000) Relation between infants' birth weight and mothers' mortality: prospective observational study. BMJ 320:839-840

5. Smith GC, Pell JP, Walsh D (2001) Pregnancy complications and maternal risk of ischaemic heart disease: a retro- spective cohort study of 129,290 births. Lancet 357:20022006

6. Smith GD, Whitley E, Gissler M, Hemminki E (2000) Birth dimensions of offspring, premature birth, and the mortality of mothers. Lancet 356:2066-2067

7. Lawlor D A, Davey Smith G, Ebrahim S (2002) Birth weight of offspring and insulin resistance in late adulthood: cross sectional survey. BMJ 325:359-362

8. Lindsay RS, Dabelea D, Roumain J, Hanson RL, Bennett PH, Knowler WC (2000) Type 2 diabetes and low birth weight: the role of paternal inheritance in the association of low birth weight and diabetes. Diabetes 49:445-449

9. Hypponen E, Smith GD, Power C (2003) Parental diabetes and birth weight of offspring: intergenerational cohort study. BMJ 326:19-20

10. Shaper AG, Pocock SJ, Walker M, Cohen NM, Wale CJ, Thomson AG (1981) British Regional Heart Study: cardiovascular risk factors in middle-aged men in 24 towns. BMJ 283:179-186

11. Walker M, Shaper AG, Lennon L, Whincup PH (2000) Twenty year follow-up of a cohort based in general practices in 24 British towns. J Public Health Med 22:479-485

12. Wannamethee SG, Lowe GD, Whincup PH, Rumley A, Walker M, Lennon L (2002) Physical activity and hemostatic and inflammatory variables in elderly men. Circulation 105:1785-1790

13. Wannamethee SG, Whincup PH, Shaper G, Walker M (1996) Influence of father's social class on cardiovascular disease in middle-aged men. Lancet 348:1259-1263

14. Whincup PH, Bruce NG, Cook DG, Shaper AG (1992) The Dinamap 1846SX automated blood pressure recorder: comparison with the Hawksley random zer sphygmomanometer under field conditions. J Epidemiol Community Health 46:164-169

15. Siedel J, Hagele EO, Ziegenhorn J, Wahlefeld AW (1983) Reagent for the enzymatic determination of serum total cholesterol with improved lipolytic efficiency. Clin Chem 29:1075-1080

16. Sugiuchi H, Uji Y, Okabe H et al. (1995) Direct measurement of high-density lipoprotein cholesterol in serum with polyethylene glycol-modified enzymes and sulfated alphacyclodextrin. Clin Chem 41:717-723

17. Warnick GR, Knopp RH, Fitzpatrick V, Branson L (1990) Estimating low-density lipoprotein cholesterol by the Friedewald equation is adequate for classifying patients on the basis of nationally recommended cutpoints. Clin Chem 36:15-19

18. Trinder P (1969) Determination of blood glucose using 4-aminophenazone as oxygen acceptor. J Clin Pathol 22:246

19. Andersen L, Dinesen B, Jorgensen PN, Poulsen F, Roder ME (1993) Enzyme immunoassay for intact human insulin in serum or plasma. Clin Chem 39:578-582

20. Emberson JR, Whincup PH, Walker M, Thomas M, Alberti KG (2002) Biochemical measures in a population-based study: effect of fasting duration and time of day. Ann Clin Biochem 39:493-501

21. Ferrara CM, Goldberg AP (2001) Limited value of the homeostasis model assessment to predict insulin resistance in older men with impaired glucose intolerance. Diabetes Care 24:245-249

22. World Health Organisation (1999) Definition, diagnosis and classification of diabetes mellitus and its complications. Part 1: Diagnosis and classification of diabetes mellitus. WHO, Geneva

23. Scholl TO, Sowers M, Chen X, Lenders C (2001) Maternal glucose concentration influences fetal growth, gestation, 
and pregnancy complications. Am J Epidemiol 154:514520

24. Dornhorst A, Rossi M (1998) Risk and prevention of type 2 diabetes in women with gestational diabetes. Diabetes Care 21 [Suppl 2]:B43-B49

25. Jackson WP (1955) A concept of diabetes. Lancet 269: 625-631

26. Kellock TD (1961) Birthweight of children of diabetic fathers. Lancet 1:1252-1254

27. Laakso M, Pyorala K (1985) Age of onset and type of diabetes. Diabetes Care 8:114-117

28. Stene LC, Magnus P, Lie RT, Sovik O, Joner G (2001) The Norwegian Childhood Diabetes Study Group. Birth weight and childhood onset type 1 diabetes: population based cohort study. BMJ 322:889-892

29. Perry IJ, Wannamethee SG, Walker MK, Thomson AG, Whincup PH, Shaper AG (1995) Prospective study of risk factors for development of non-insulin dependent diabetes in middle aged British men. BMJ 310:560-564

30. O'Sullivan JJ, Pearce MS, Parker L (2000) Parental recall of birth weight: how accurate is it? Arch Dis Child 82:202-203

31. Butler NR, Alberman ED (1969) Perinatal problems: the second report of the 1958 British perinatal mortality survey. Livingstone, London

32. Leon DA, Lithell HO, Vagero D et al. (1998) Reduced fetal growth rate and increased risk of death from ischaemic heart disease: cohort study of 15,000 Swedish men and women born 1915-29. BMJ 317:241-245

33. Eriksson JG, Forsen T, Toumilehto J, Osmond C, Barker DJ (2001) Early growth and coronary heart disease in later life: longitudinal study. BMJ 322:949-953

34. Hattersley AT, Beards F, Ballantyne E, Appleton M, Harvey R, Ellard S (1998) Mutations in the glucokinase gene of the fetus result in reduced birth weight. Nat Genet 19:268-270

35. Dunger DB, Ong KK, Huxtable SJ et al. (1998) Association of the INS VTNR with size at birth. ALSPAC Study Team. Avon Longitudinal Study of Pregnancy and Childhood. Nat Genet 19:98-100

36. Ong KK, Phillips DI, Fall C et al. (1999) The insulin gene VNTR, type 2 diabetes and birth weight. Nat Genet 21: 262-263

37. Casteels K, Ong K, Phillips D, Bendall H, Pembrey M (1999) Mitochondrial 16189 variant, thinness at birth, and type-2 diabetes. ALSPAC study team. Avon Longitudinal Study of Pregnancy and Childhood. Lancet 353:14991500

38. Lindsay RS, Hanson RL, Wiedrich C, Knowler WC, Bennett PH, Baier LJ (2003) The insulin gene variable number tandem repeat class I/III polymorphism is in linkage disequilibrium with birth weight but not type 2 diabetes in the PIMA population. Diabetes 52:187-193 